\title{
Cancer and Leukemia Group B
}

National Cancer Institute

\section{Source}

National Cancer Institute. Cancer and Leukemia Group B. NCI Thesaurus. Code C25442.

A national clinical research group - network of 29 university medical centers, over 185 community hospitals and more than almost 3000 physicians - sponsored by the $\mathrm{NCl}$, with its Central Office headquartered at the University of Chicago, and its Statistical Center located at Duke University, founded in 1955 with a goal of bring ing together clinical and laboratory research. 